\title{
Clival chordomas: considerations after 16 years of endoscopic endonasal surgery
}

\author{
Matteo Zoli, MD,' Laura Milanese, MD, ${ }^{1}$ Rocco Bonfatti, MD, ${ }^{1}$ Marco Faustini-Fustini, MD, ${ }^{1}$ \\ Gianluca Marucci, MD, PhD, ${ }^{2}$ Giovanni Tallini, MD, ${ }^{3}$ Corrado Zenesini, MSc, ${ }^{4}$ Carmelo Sturiale, MD, ${ }^{1}$ \\ Giorgio Frank, MD, ${ }^{1}$ Ernesto Pasquini, MD, ${ }^{5}$ and Diego Mazzatenta, MD ${ }^{1}$ \\ ${ }^{1}$ Center of Pituitary and Endoscopic Skull Base Surgery, IRCCS Istituto delle Scienze Neurologiche di Bologna; ${ }^{2}$ Anatomic \\ Pathology, Bellaria Hospital, University of Bologna; ${ }^{3}$ Department of Medicine (DIMES), Anatomic Pathology-Molecular Diagnostic \\ Unit, AUSL of Bologna, University of Bologna School of Medicine; ${ }^{4}$ Epidemiology and Biostatistics Service, IRCCS Istituto delle \\ Scienze Neurologiche di Bologna; and ${ }^{5}$ ENT Department, Ospedale Bellaria, Bologna, Italy
}

OBJECTIVE In the past decade, the role of the endoscopic endonasal approach (EEA) has relevantly evolved for skull base tumors. In this study, the authors review their surgical experience with using an EEA in the treatment of clival chordomas, which are deep and infiltrative skull base lesions, and they highlight the advantages and limitations of this ventral approach.

METHODS All consecutive cases of chordoma treated with an EEA between 1998 and 2015 at a single institution are included in this study. Preoperative assessment consisted of neuroimaging (MRI and CT with angiography sequences) and endocrinological, neurological, and ophthalmological evaluations, which were repeated 3 months after surgery and annually thereafter. Postoperative adjuvant therapies were considered.

RESULTS Sixty-five patients (male/female ratio 1:0.9) were included in this study. The median age was 48 years (range $9-80$ years). Gross-total resection (GTR) was achieved in 47 cases $(58.7 \%)$. On univariate analysis, primary procedures $(p=0.001)$, location in the superior or middle third of the clivus $(p=0.043)$, extradural location $(p=0.035)$, and histology of conventional chordomas ( $p=0.013$ ) were associated with a higher rate of GTR. The complication rate was $15.1 \%$, and there were no perioperative deaths. Most complications did not result in permanent sequelae and included 2 CSF leaks (2.5\%), 5 transient cranial nerve VI palsies (6.2\%), and 2 internal carotid artery injuries $(2.5 \%)$, which were treated with coil occlusion of the internal carotid artery without neurological deficits. Three patients (3.8\%) presented with complications resulting in permanent neurological deficits due to a postoperative hematoma (1.2\%) causing a hemiparesis, and 2 permanent ophthalmoplegias (2.5\%). Seventeen patients (26.2\%) have died of tumor progression over the course of follow-up (median 52 months, range 7-159 months). Based on Kaplan-Meier analysis, the survival rate was $77 \%$ at 5 years and $57 \%$ at 10 years. On multivariate analysis, the extent of tumor removal $(p=0.001)$ and the absence of previous treatments $(p=0.001)$ proved to be correlated with a longer survival rate.

CONCLUSIONS The EEA was associated with a high rate of tumor removal and symptom control, with low morbidity and preservation of a good quality of life. These results allow for a satisfactory overall survival rate, particularly after GTR and for primary surgery. Considering these results, the authors believe that an EEA can be a helpful tool in chordoma surgery, achieving a good balance between as much tumor removal as possible and the preservation of an acceptable patient quality of life.

https://thejns.org/doi/abs/10.3171/2016.11.JNS162082

KEY WORDS clivus chordoma; endoscopic endonasal approach; quality of life; surgical complications; survival rate; surgical outcome; CSF leak; oncology

$\mathrm{B}$ ECAUSE of their origin and pattern of growth, clival chordomas are an ideal target for the endoscopic endonasal approach (EEA). $5,11,13,20,23,24,29$ Unlike other more aggressive transcranial approaches, the EEA allows ventral exposure of these deep tumors, avoiding brain retraction or major vascular and neural manipulation. $1,6,9,13,18,21,22,25,27,28$ The EEA also facilitates wide tumor resection following the path of growth of these insidious tumors. $5,11,13,20,23,24,29$

Although several reports have detailed the feasibility

ABBREVIATIONS CN = cranial nerve; $C S$ = cavernous sinus; EEA = endoscopic endonasal approach; GTR = gross-total resection; ICA = internal carotid artery; PTR = partial tumor resection; $\mathrm{QOL}=$ quality of life; STR = subtotal resection.

SUBMITTED August 28, 2016. ACCEPTED November 11, 2016.

INCLUDE WHEN CITING Published online April 14, 2017; DOI: 10.3171/2016.11.JNS162082. 
and safety of the EEA for the treatment of clival chordomas, few studies have evaluated the mid- and long-term results in order to assess the effectiveness of this approach in achieving tumor control and to study prognostic factors. ${ }^{2-4,7,8,10,12,13,16,26,27,30}$ In this study, we review our 16-year experience with 65 consecutive patients with clival chordomas treated with the EEA. We detail the evolution of this approach over time, demonstrating not only expansion of the indications but also the progressive better understanding of its advantages and limitations.

\section{Methods}

We retrospectively reviewed every patient with a diagnosis of chordoma treated with an EEA between 1998 and December 2015 in the Center of Pituitary and Endoscopic Skull Base Surgery of the IRCCS Istituto delle Scienze Neurologiche di Bologna, Italy. All procedures were performed by the senior authors (G.F., E.P., and D.M.).

During the 16 years of this study, our attitude toward EAA progressively improved and evolved. Initially, EEA was mostly reserved for extradural midline chordomas of the upper and middle thirds of the clivus. Increased experience and technical improvements led us to extend the indication to tumors involving the inferior third and the craniovertebral junction as well as to lesions with intradural extension, including in patients with clear brainstem invasion. Over time, an increasing number of tumors with paramedian extension have been considered suitable for EEA, starting with tumors involving the cavernous sinus (CS) and then broadening the indications to tumors extending into the infratemporal and pterygopalatine fossae, the jugular foramen, and the occipital condyles. It appears that a distinct transition to the use of the EEA in the treatment of more complex lesions occurred in 2007 after a 9-year learning curve.

Prior to surgery, comprehensive written informed consent was obtained for the surgical removal of tissue samples and the related diagnostic procedures. All information regarding the human material used in this study was managed using anonymous numerical codes, and samples were handled in compliance with the Declaration of Helsinki. The diagnosis of chordoma was histologically revised in all cases by a board-certified pathologist with particular experience in skull base tumors.

All patients underwent a preoperative multidisciplinary evaluation that included neurological examination, complete endocrinological baseline tests (serum prolactin, cortisol, thyroid-stimulating hormone, adrenocorticotropic hormone, free thyroxine, growth hormone, luteinizing hormone, follicle-stimulating hormone, and gonadotropins, and possible signs of diabetes insipidus) and evaluation for tumors involving the sellar compartment, and ophthalmological examination for tumors with radiologically proven compression of the optic apparatus. Preoperative neuroradiological assessment included brain MRI and CT angiography sequences to check for bone erosion and displacement of the carotid arteries, respectively. Careful notes were made about the type and degree of previous treatments for the target lesion, including surgery, radiation therapy, and other medical treatment. Complications were assessed based on the postoperative clinical reports.
Neurological, endocrinological, and ophthalmological evaluations as well as MRI were repeated 3 months after surgery and annually thereafter to assess the clinical outcome and extent of tumor resection.

Gross-total resection (GTR) was defined as no visible tumor remnant on postoperative MRI as assessed by a board-certified neuroradiologist, and subtotal resection (STR) was defined as residual tumor of less than $20 \%$ of the original mass detected on postoperative imaging. Partial tumor resection (PTR) was defined as residual tumor greater than $20 \%$.

Postoperative adjuvant therapy (standard radiotherapy, proton beam radiotherapy, or other treatments) were considered in every case after resection. Quality of life (QOL) at follow-up was evaluated using the Katz index of independence in activities of daily living (Table 1). ${ }^{17}$

To identify prognostic factors predictive of the extent of resection and survival, demographic (sex and age), clinical (previous treatment of any type), radiological (extent of clival involvement and intradural invasion), and histological (tumor histology and proliferative index) parameters were collected.

\section{Surgical Approach}

Our surgical technique was reported elsewhere. ${ }^{12}$ Briefly, the patient was placed in the semisitting position, with the thorax slightly elevated. After oral endotracheal anesthesia, the laryngopharynx was packed with gauze. Routinely, we use neuronavigation (StealthStation S7, Medtronic), based on CT angiography results, processed through StealthMerge Software (Medtronic) and neurophysiological monitoring. The extent and subtype of approach depended on the location of the tumor in the upper, middle, or lower clivus and on its lateral extension (Fig. 1).

For tumors located in the upper clivus, we performed a standard endoscopic midline transsphenoidal approach with displacement or resection of the middle concha, followed by a posterior septostomy and a wide anterior sphenoidotomy. Extradural intraosseous chordomas can usually be identified after drilling the upper clivus as much as necessary, while intradural tumors require exposure and opening of the dura (Fig. 2A and B). For extradural tumors in the upper third of the clivus, the lateral limit of the exposure is the paraclival carotid artery, while for intradural extension the lateral limit is determined by a sagittal plane intersecting cranial nerve (CN) III, which should be respected in order to avoid injury of the nerve

\section{TABLE 1. Levels of functional outcome}

\begin{tabular}{cc}
\hline Level & Functional Outcome \\
\hline 1 & $\begin{array}{c}\text { Complete autonomy in daily activities \& social \& at work/school } \\
\text { tasks }\end{array}$ \\
\hline 2 & Partial autonomy in daily activities \& social \& work/school tasks \\
\hline 3 & $\begin{array}{c}\text { Occasional external support necessary for daily life \& impos- } \\
\text { sibility to fulfill any social \& work/school tasks, i.e., a semi- } \\
\text { dependent condition }\end{array}$ \\
\hline 4 & $\begin{array}{c}\text { Daily life absolutely dependent on continuous external support, } \\
\text { i.e., a condition of absolute dependence }\end{array}$ \\
\hline
\end{tabular}

Adapted from Katz et al., 1963. 


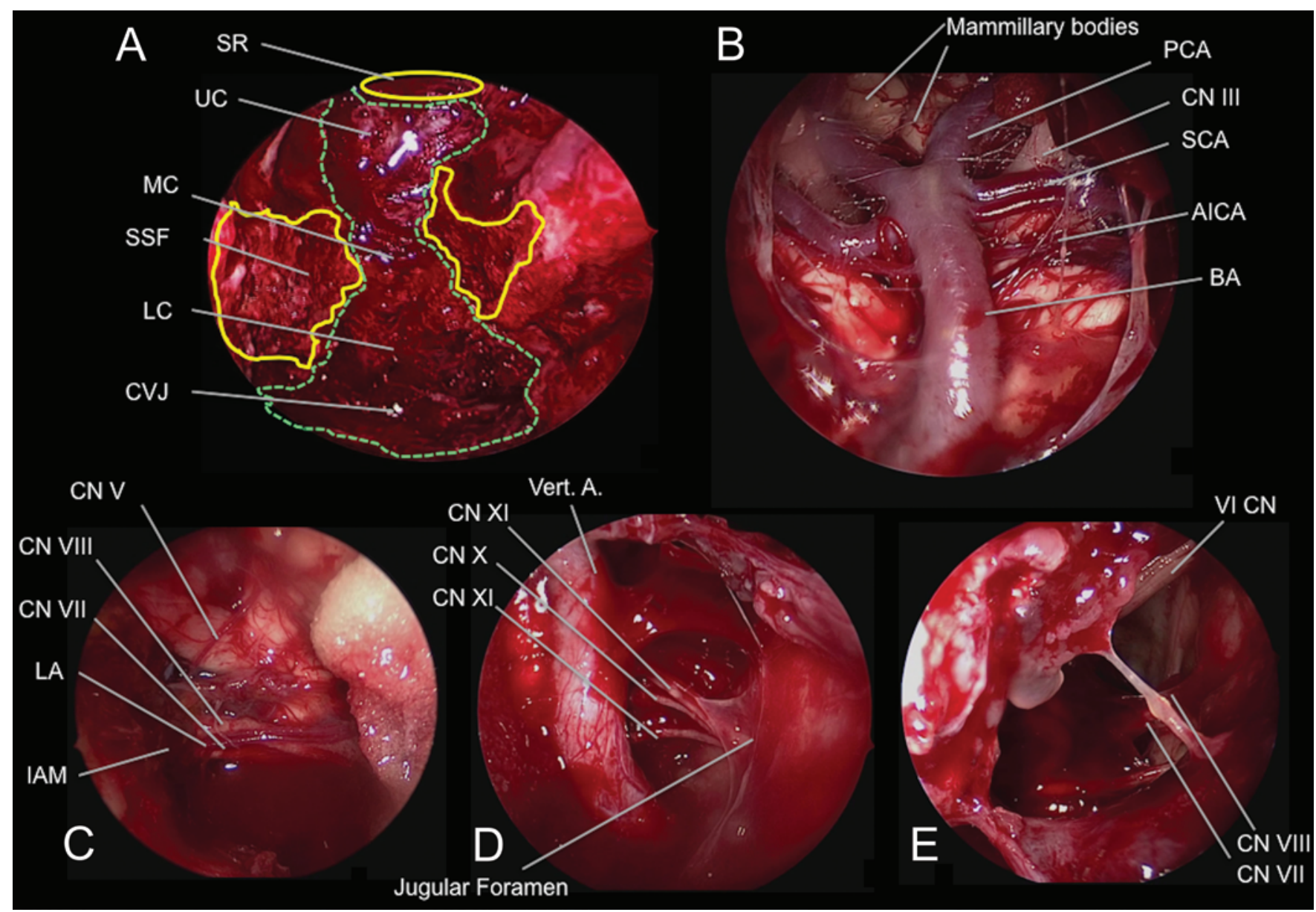

FIG. 1. Intraoperative endoscopic endonasal images. A: $0^{\circ}$ scope. After removal of a clival chordoma extending from the sellar region to the craniovertebral junction, the 3 different portions of the clivus are visible. B: $30^{\circ}$ scope. The intradural structures of the upper clivus are visible, such as the interpeduncular cistern, containing the basilar artery apex and CN III as well as the midbrain and upper portion of the pons. C: $30^{\circ}$ scope. The right cerebellopontine angle is illustrated, and CNs VII and VIII, running toward the internal acoustic meatus, are shown. D: $30^{\circ}$ scope. The brainstem and the vasculonervous structures of the inferior clivus (left vertebral artery and CNs IX, X, and XI) are visibile. E: $30^{\circ}$ scope. Left CN VI can be observed as the intradural lateral limit of the approach to the middle third of the clivus. $\mathrm{AICA}=$ anterior inferior cerebellar artery; $\mathrm{BA}=$ basilar artery; $\mathrm{CVJ}=$ craniovertebral junction; $\mathrm{IAM}=$ internal acoustic meatus; $\mathrm{LA}=$ labyrinthine artery; $\mathrm{LC}=$ lower clivus; $\mathrm{MC}=$ middle clivus; $\mathrm{PCA}=$ posterior cerebral artery; SCA = superior cerebellar artery; $\mathrm{SR}$ = sellar region; SSF = sphenoid sinus floor; $U C=$ upper clivus; Vert. $A$. = vertebral artery. Figure is available in color online only.

(Fig. 2C and D). Further, lateral extension of this approach can be achieved through an ethmoid-pterygo-sphenoidal route, consisting of an ethmoidectomy followed by medial maxillectomy and drilling of the tip of the vertical process of the palatine bone and of the medial pterygoid process.

For middle clivus chordomas, we used an extended transsphenoidal approach by drilling the sphenoidal floor between the paraclival tract of the internal carotid arteries (ICAs), using the vidian nerve as a landmark (Figs. 3A, 3B, 4, and 5). For extradural lesions, the lateral limit of this approach is represented by the ICAs, while for intradural tumors, the lateral limit is a sagittal plane intersecting $\mathrm{CN}$ VI. It is not uncommon for chordomas involving the middle clivus to spread to surrounding areas, especially the pterygopalatine and the infratemporal fossa. In such cases, addition of a transmaxillo-pterygoid approach is advantageous.

Lesions situated in the inferior third of the clivus or involving the craniovertebral junction can be exposed through skeletonization of the rhinopharynx. We prefer to dissect the muscle planes, performing a rhinopharynx flap with an inverted U shape, starting behind one eustachian tube to the other (Fig. 6). This flap can be displaced downward during tumor removal and repositioned with sutures at the end of the surgery to support the multilayer plastic repair. As in other segments of the clivus, the ICA in its parapharyngeal tract represents the main lateral extradural limit of this approach, while for intradural lesions the lateral limit is the plane intersecting CNs IX, X, and XI and, inferiorly, CN XII.

In case of intraoperative CSF leakage, a watertight plastic repair is mandatory. We use a multilayer technique with fascia lata, eventually abdominal fat and a piece of cartilage or bone, and a pedicled flap or a free graft of mucoperiosteum obtained from the septum or middle turbinate. The nasal cavity is filled with Gelfoam and Merocel (Merocel Corp.). 

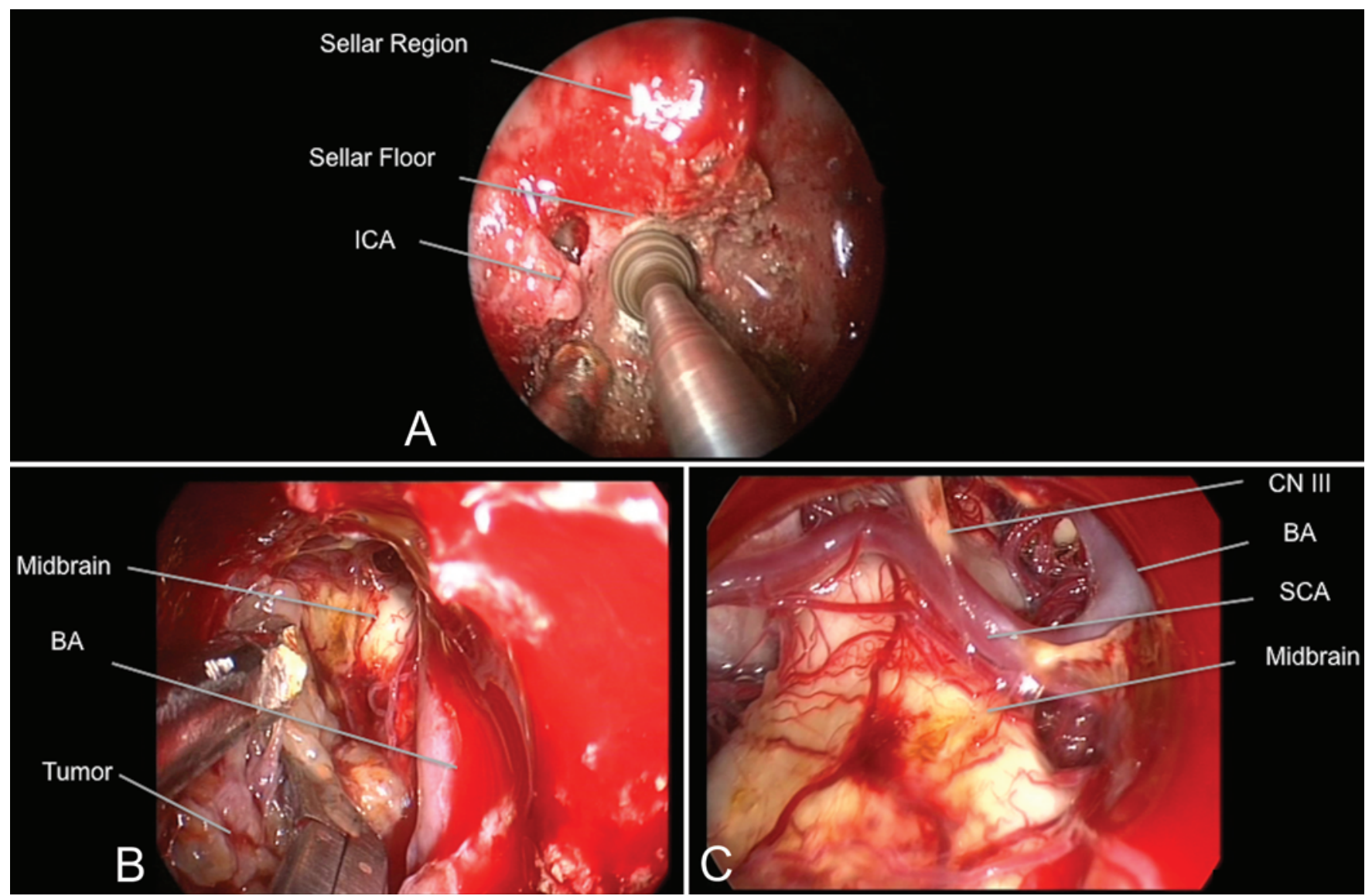

FIG. 2. Intraoperative endoscopic endonasal images. Surgical approach to the upper clivus. A: $0^{\circ}$ scope. The bone of the sellar floor is drilled out to expose the tumor. The carotid artery represents the extradural lateral limit of this approach. B: $0^{\circ}$ scope. The tumor is progressively dissected from the neuromuscular structures and removed. C: $30^{\circ}$ scope. After tumor removal, it is possible to explore the interpeduncular cistern. Figure is available in color online only.

\section{Statistical Analysis}

Continuous variables are presented as median and range, while categorical variables are reported as absolute frequency and relative frequency. Fisher's exact test was used to evaluate the association between GTR and other variables (age, sex, other preoperative treatments, clivus location, relationship with the dura layer, histotype, and replicability index) when the unit of analysis was the procedure.

The survival function was calculated with Kaplan-Meier estimates and compared for each variable (age, sex, other preoperative treatments, clivus location, relationship to the dura, histotype, replicability index, and extent of tumor removal) using the log-rank test when the unit of analysis was the patient. Univariate and multivariate Cox regression analyses were performed to study the association between the death rate and previously mentioned risk factors.

All $\mathrm{p}$ values are based on 2-sided tests, and $\mathrm{p}<0.05$ was considered significant. Statistical analysis was performed using the statistical package Stata/SE (version 14.0, StataCorp).

\section{Results}

Between 1998 and December 2015, 65 patients (34 males and 31 females; median age 48 years, range 9-80 years) with clival chordomas were treated with 80 en- doscopic endonasal procedures. Thirty-seven patients (56.9\%) underwent primary procedures, while 28 (43.1\%) patients had undergone previous treatments (after surgery alone in 15 , after surgery and radiation therapy in 12 , and after radiation therapy alone in 1). Most lesions were located in the superior and middle thirds of the clivus (45 cases, $56.3 \%$ ), as summarized in Table 2. The tumors were extradural in 55 cases $(68.8 \%)$, and of these, $43(53.8 \%)$ presented with an infiltration of the dura without trespassing. Intradural extension was present in 25 cases $(31.2 \%)$ (Table 3). The brainstem was invaded in 2 cases $(2.5 \%)$.

Preoperative clinical findings are summarized in Table 4. The most common symptom at presentation was ophthalmoparesis (35 patients, 53.8\%). Symptoms and signs of pituitary dysfunction were present in 6 patients $(9.2 \%)$ and visual disturbances were observed in 12 patients (18.5\%).

Histological findings are reported in Table 5. Among the 15 patients who had undergone multiple surgeries for tumor progression or recurrence, the tumor histotype changed from conventional to dedifferentiated chordoma in 1 case. Furthermore, in 8 of these 15 patients the proliferative index, evaluated by Ki-67 staining, increased after each surgery. MRI at 3 months revealed GTR in 47 (58.7\%), STR in 28 (35\%), and PTR in 5 (6.2\%) cases, respectively.

On univariate analysis, the main elements showing a 

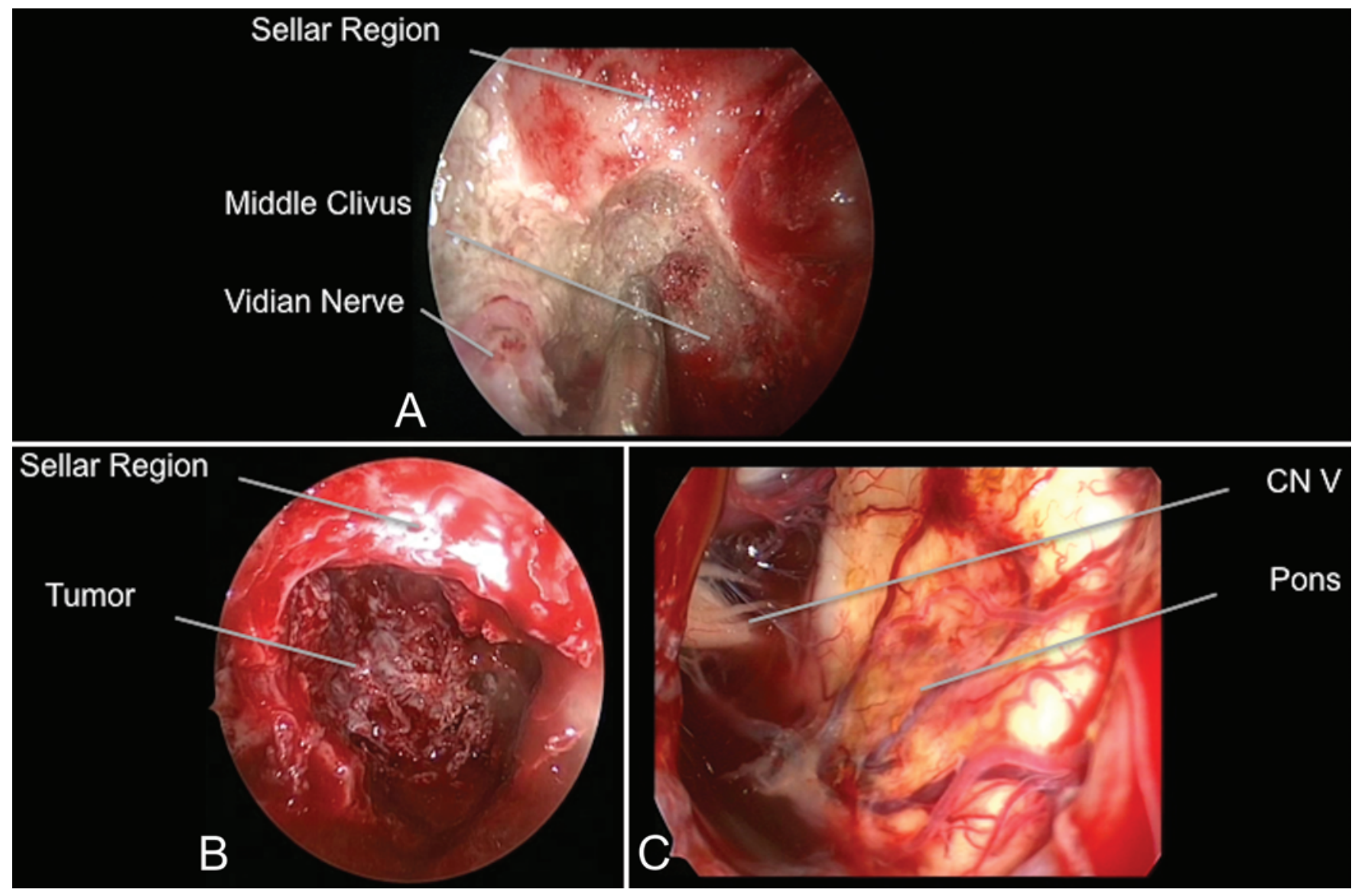

FIG. 3. Intraoperative endoscopic endonasal images. Surgical approach to the middle clivus. A: $0^{\circ}$ scope. After identification of the main anatomical landmark, the vidian nerve, the middle clivus can be drilled out. B: $0^{\circ}$ scope. The tumor is removed with curettes and dissection instruments. The carotid artery is the extradural border of this approach. C: $30^{\circ} \mathrm{scope}$. After tumor removal, the pons and the trigeminal nerve are visible. Figure is available in color online only.

significant correlation with the GTR rate were absence of previous treatments $(\mathrm{p}=0.001)$, location in the superior or middle third of the clivus $(\mathrm{p}=0.043)$, extradural location $(\mathrm{p}=0.035)$, and histology of conventional chordoma $(\mathrm{p}=$ $0.013)$.
The overall surgical morbidity was $15.1 \%$, and there were no perioperative deaths (Table 6). Most complications did not result in permanent sequelae and included 2 CSF leaks (2.5\%), 5 transient CN VI palsies (6.2\%), and 2 ICA injuries (2.5\%), which were treated with coil
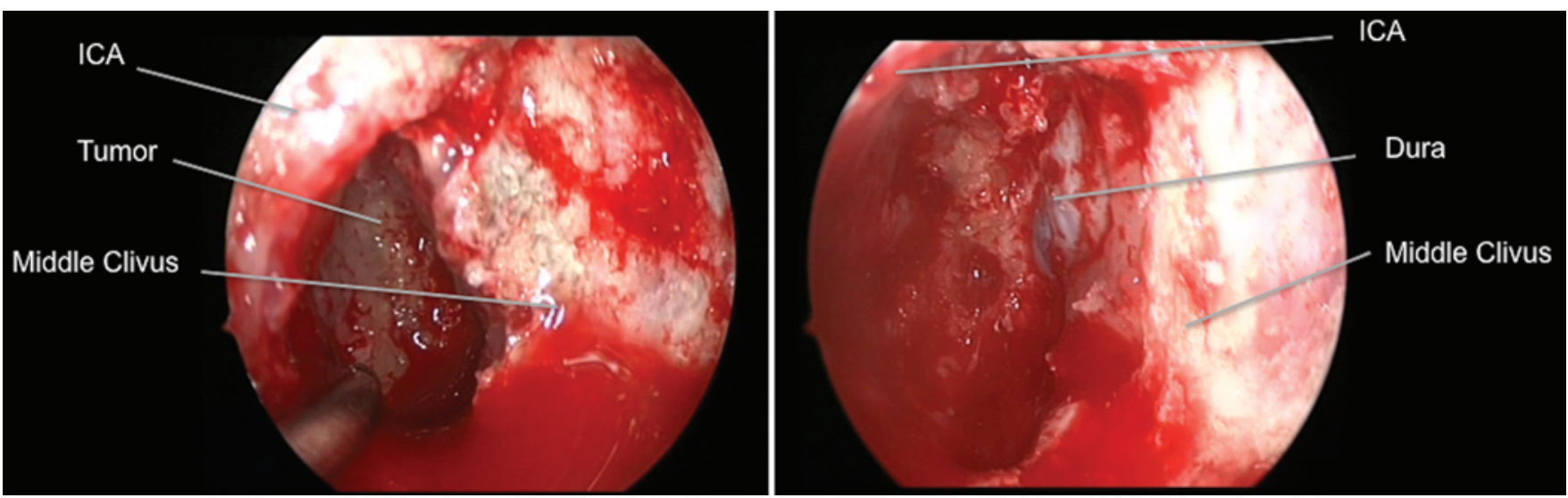

FIG. 4. Intraoperative endoscopic endonasal images. Left: $30^{\circ}$ scope. The carotid artery is a relative lateral limit of the EEA in the extradural space. Indeed, as in this case it is possible to remove portions of the tumor behind the vessel with an angled optic and other angled instruments. Right: $30^{\circ}$ scope. The tumor is completely resected, and the dura of the poster fossa is exposed. Figure is available in color online only. 


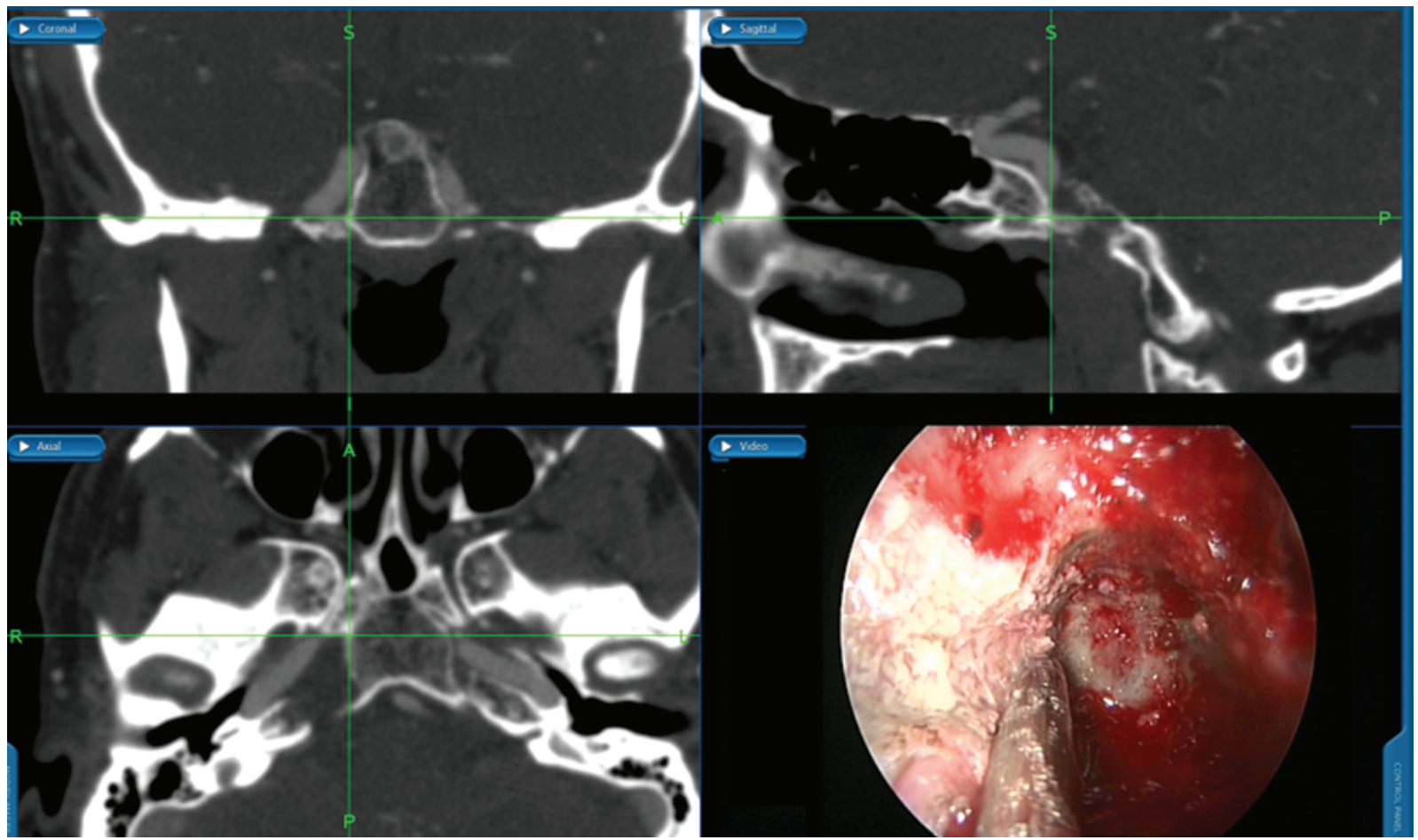

FIG. 5. Intraoperative endoscopic endonasal and neuronavigation images. The vidian nerve is a helpful landmark for the middle clivus approach, allowing the identification of the genu between the petrosal and paraclival carotid, and thus identifying a medial safe area. Figure is available in color online only.

occlusion of the ICA without neurological deficits. One ICA injury occurred in the early phase of our experience, and the other occurred while removing a dedifferentiated chordoma at the petroclival junction that had invaded the vessel wall. Complications resulted in permanent neurological deficits in 3 cases (3.8\%). These included a postoperative hematoma $(1.2 \%)$ resulting in a hemiparesis, and 2 permanent ophthalmoplegias (2.5\%).

All but 5 patients who had undergone primary treatment were treated with postoperative proton therapy. Three patients were treated with conventional radiotherapy because of patient preference, and the remaining 2 patients had poor Karnofsky Performance Scale scores.

After a mean follow-up of 52 months (median 48 months, range 7-159 months), 4 (6.2\%) de novo endocrinological deficits were observed. Visual function normalized or improved in 4 of the 12 cases (33\%), while it remained unchanged in the other cases. Two cases of de novo ophthalmic deficits were observed (3.1\%). As reported in Table 7, ophthalmoplegia resolved postoperatively in 7 cases $(20 \%)$ and improved in 6 cases (17\%).

During the follow-up, a total of 24 patients (40\%) presented with a recurrence/tumor remnant growth after a median time of 20.5 months (range 12-55 months). Twentytwo patients experienced regrowth after a PTR, and 4 had a recurrence after an MRI-documented GTR. Seventeen patients died of tumor recurrence/progression (26.2\%). Based on Kaplan-Meier analysis, survival rates were $77 \%$ at 5 years and $57 \%$ at 10 years (Fig. 7). Among all factors, only the extent of tumor resection and primary treatment correlated independently with increased survival in multivariate analysis ( $\mathrm{p}=0.001$ for both) (Table 8$)$. At follow-up, independent performance of activities of daily living was normal, with complete return to the previous social and working level in 37 patients (57\%); worsening was observed in 7 patients $(10.7 \%)$. One patient $(1.5 \%)$ was partially dependent and $3(4.6 \%)$ were fully dependent and needed constant assistance from a caregiver for routine daily activities.

\section{Discussion}

In a consecutive series of 65 patients who underwent an EEA during a 16-year period, we observed a low rate of complications with permanent neurological sequelae $(3.8 \%)$ and a satisfactory rate of GTR (58.7\%). Over this time, our attitude toward EEA progressively evolved, leading to the extension of its indications and to the inclusion of more complex chordomas. This evolution began with purely midline extradural tumors located in the sphenoid sinus, followed by cases with lateral extension, such as the $\mathrm{CS}$, and then infratemporal and pterygopalatine fossae and jugular foramen tumors. Finally, we extended our approach inferiorly all the way to the craniocervical junction and to intradural lesions. We noted that we had broadened our indications to include more complex tumors after 9 years, concurrently with a significant increase in our surgical experience and technological advances. Our strategy was based on the considerations that EEA represents a more direct route and is less invasive with a favorable complication rate compared with other transcranial and more invasive approaches. ${ }^{1,6,9,13,18,21,22,25,27,28}$

In this study, we observed that the location of the tumor in the inferior third of the clivus, its intradural extension, and previous treatment (surgery and/or radiation therapy) 

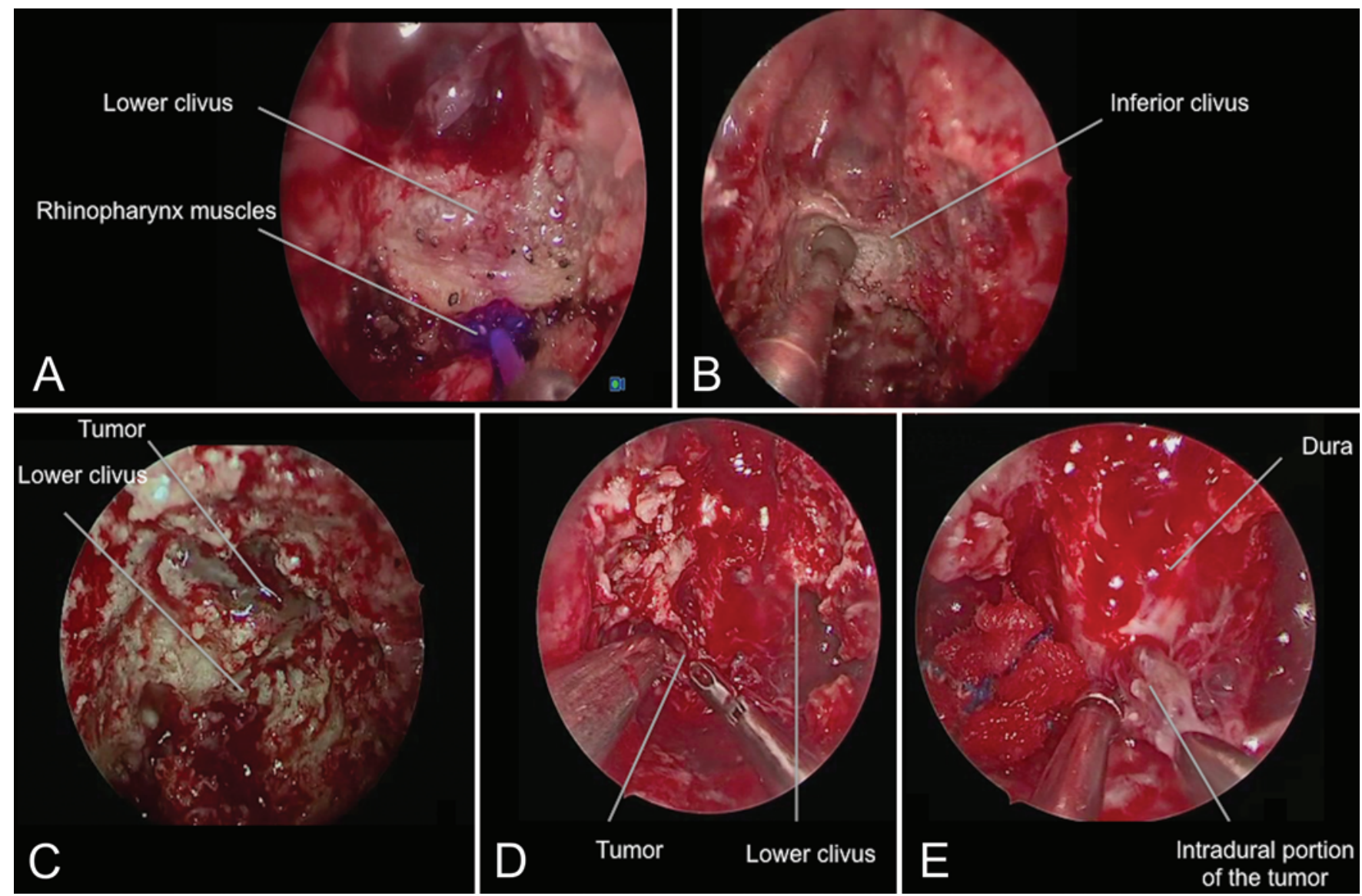

FIG. 6. Intraoperative endoscopic endonasal images. Approach to the lower clivus. $0^{\circ}$ scope. A: The rhinopharyngeal muscle layer is progressively dissected and turned downward to expose the lower clivus. B and C: The bone is drilled out, tailoring the extension of the approach to the tumor location. D: The tumor is removed with dissection instruments. E: Intradural extension of the tumor can be followed to achieve GTR. Figure is available in color online only.

correlated with less tumor removal. In a meta-analysis, Komotar et al. observed that GTR was achieved in a significantly greater percentage of EEA patients $(61 \%)$ than in open surgery patients. This result, which is similar to ours, confirms the replicability and standardization of the results among different experienced centers with EEA. ${ }^{19}$ That study yielded an overall survival rate after open surgery of $72.7 \%$ at 3 years and $65.7 \%$ at 5 years. ${ }^{4,15,19}$ In our experience, we observed a similar survival rate at 5 years on Kaplan-Meier analysis, allowing assessment of the positive results of our multimodal strategy (EEA followed by radiation therapy). Due to the short follow-up of our study, the survival rate at 10 years should be considered as a preliminary report, and further series are necessary to confirm these data. In our series, among all tested parameters, GTR and an absence of previous treatments

TABLE 2. Localization in the clivus observed in our series

\begin{tabular}{cc}
\hline Clivus & No. of Procedures (\%) \\
\hline Upper & $3(3.8)$ \\
\hline Middle & $42(52.5)$ \\
\hline Lower & $12(15)$ \\
\hline Holoclival & $23(28.8)$ \\
\hline
\end{tabular}

correlated with better survival rates on multivariate analysis. Although we have observed that other factors, such as location in the superior of middle third of the clivus ( $\mathrm{p}=$ $0.043)$, extradural location $(\mathrm{p}=0.035)$, and histology of conventional chordoma $(p=0.013)$, can influence the GTR rate, these parameters were not independently associated with a better survival rate. This leads to 2 considerations: the goal of surgery for chordoma should be radical surgery whenever possible, followed by radiation therapy; for primary cases, the goal of GTR is highly desirable. ${ }^{15}$

One of the main advantages of the EEA is the low complication rate compared with other more invasive approaches. Indeed, CSF leakage in our study occurred only in 2 cases $(2.5 \%)$, one early in 2007 and the other in the most

\section{TABLE 3. Relationship with the dura mater}

\begin{tabular}{lc}
\hline \multicolumn{1}{c}{ Location } & No. of Procedures (\%) \\
\hline Extradural extension & $12(15)$ \\
\hline $\begin{array}{l}\text { Extradural extension w/ dural infiltra- } \\
\text { tion }\end{array}$ & $43(53.8)$ \\
\hline Limited intradural extension & $22(27.5)$ \\
\hline Prevalent intradural extension & $2(2.5)$ \\
\hline Purely intradural extension & $1(1.2)$ \\
\hline
\end{tabular}


TABLE 4. Preoperative symptoms

\begin{tabular}{lc}
\hline \multicolumn{1}{c}{ Preop Symptom } & No. of Patients (\%) \\
\hline Endocrinological & $59(90.8)$ \\
\hline None & $5(7.7)$ \\
\hline Partial hypopituitarism & $1(1.5)$ \\
\hline Panhypopituitarism & $53(81.5)$ \\
\hline Visual & $6(9.3)$ \\
\hline None & $3(4.6)$ \\
\hline Quadrantanopia or monolateral hemianopia & $2(3.1)$ \\
\hline Bitemporal hemianopia & $1(1.5)$ \\
\hline Bilat quadrantanopia (>2 quadrants) & \\
\hline Monolat quadrantanopia (>2 quadrants) w/ \\
$\quad$ controlat quadrantanopia (<2 quadrants) \\
\hline Neurological & $14(21.5)$ \\
\hline None & $35(53.8)$ \\
\hline Ophthalmoplegia w/ or w/o trigeminal neuralgia & $1(1.5)$ \\
\hline Dysphagia/dysphonia & $9(13.8)$ \\
\hline Diplopia/dysphagia/dysphonia & $4(6.2)$ \\
\hline Hemiparesis & $2(3.1)$ \\
\hline CN VII-VIII deficit &
\end{tabular}

recent part of our experience in 2013. Permanent neurological deficits in our study occurred in $3.8 \%$ of cases, consisting of 2 permanent CN VI palsies and 1 severe hemiparesis due to postoperative hemorrhage. We observed, as reported by Gardner et al., ${ }^{14}$ that the risk of ICA injury is higher for chordomas than for other tumors treated through an EEA. In our experience, 1 ICA injury occurred in the early part of our experience, when the technique and technological instrumentation were still not adequately developed. The other injury was related to invasion of the vessel wall by a

TABLE 5. Histological features

\begin{tabular}{cc}
\hline \multicolumn{1}{c}{ Feature } & No. of Procedures (\%) \\
\hline Histotype & $69(86.2)$ \\
\hline Conventional chordoma & $4(5)$ \\
\hline Chondroid chordoma & $5(6.2)$ \\
\hline Dedifferentiated chordoma & \\
\hline Ki-67 & $30(37.5)$ \\
\hline$<3 \%$ & $25(31.2)$ \\
\hline $3-5 \%$ & $19(23.8)$ \\
\hline $5-10 \%$ & $4(5)$ \\
\hline$>10 \%$ & $27(33.8)$ \\
\hline Infiltration & $32(40)$ \\
\hline None & $18(22.5)$ \\
\hline Bone & $1(1.32)$ \\
\hline Dura & $1(1.2)$ \\
\hline Muscle & $17(21.2)$ \\
\hline Dura \& muscle & $61(76.2)$ \\
\hline Necrosis &
\end{tabular}

TABLE 6. Complications of the series

\begin{tabular}{lc}
\hline \multicolumn{1}{c}{ Complication } & No. of Procedures (\%) \\
\hline CSF leak & $2(2.5)$ \\
\hline ICA injury & $2(2.5)$ \\
\hline Hematoma & $1(1.2)$ \\
\hline CN VI palsy & $5(6.2)$ \\
\hline Transient & $2(2.5)$ \\
\hline Permanent & $9(11.3)$ \\
\hline Complications w/o sequelae & $3(3.8)$ \\
\hline Complications w/ sequelae
\end{tabular}

dedifferentiated chordoma. QOL was preserved at preoperative levels in the majority of cases, due to the low morbidity rate and the good tolerability of this approach. Unfortunately, the retrospective nature of this study allowed us to adopt the Katz index only during the patient's follow-up. Future studies focused on the neuropsychological outcome of this surgery are desirable to investigate this topic more accurately.

Our study has some limitations related to the inability to adequately assess more long-term survival (longer than 10 years) and the lack of a control group of patients treated with transcranial approaches or managed differently. Nevertheless, given the relatively large number of patients treated by our multidisciplinary team, we can conclude that the EAA has been shown to be effective in achieving good rates of GTR with an acceptable low complication rate.

\section{Conclusions}

This series illustrates our progressive evolution with increasing experience and development of dedicated tools to include more complex lesions but only after 9 years of early experience mostly with purely midline lesions. Despite all of the advances, results of modern surgery, including endoscopic endonasal treatment of clival chordomas, are far from ideal with high rates of progression and recurrence at follow-up. However, we have shown that EEA can achieve a good balance between the highly desirable goal of a tumor removal (i.e., as much as possible) and the preservation of an acceptable QOL for the patient.

\section{TABLE 7. Neurological outcomes}

\begin{tabular}{lcccc}
\hline \multirow{2}{*}{ Outcome } & \multicolumn{5}{c}{ No. of Patients } \\
\cline { 2 - 5 } & Normalized & Improved & Unchanged & Worsened \\
\hline None & 0 & 0 & 12 & 2 \\
\hline $\begin{array}{c}\text { Ophthalmoplegia w/ } \\
\text { or w/o trigeminal } \\
\text { neuralgia }\end{array}$ & 7 & 6 & 22 & 0 \\
\hline $\begin{array}{c}\text { Dysphagia/dys- } \\
\text { phonia }\end{array}$ & 0 & 0 & 1 & 0 \\
\hline $\begin{array}{c}\text { Diplopia/dysphagia/ } \\
\text { dysphonia }\end{array}$ & 2 & 2 & 5 & 0 \\
\hline Hemiparesis & 0 & 1 & 3 & 0 \\
\hline CN VII-VIII deficit & 2 & 0 & 0 & 0 \\
\hline
\end{tabular}



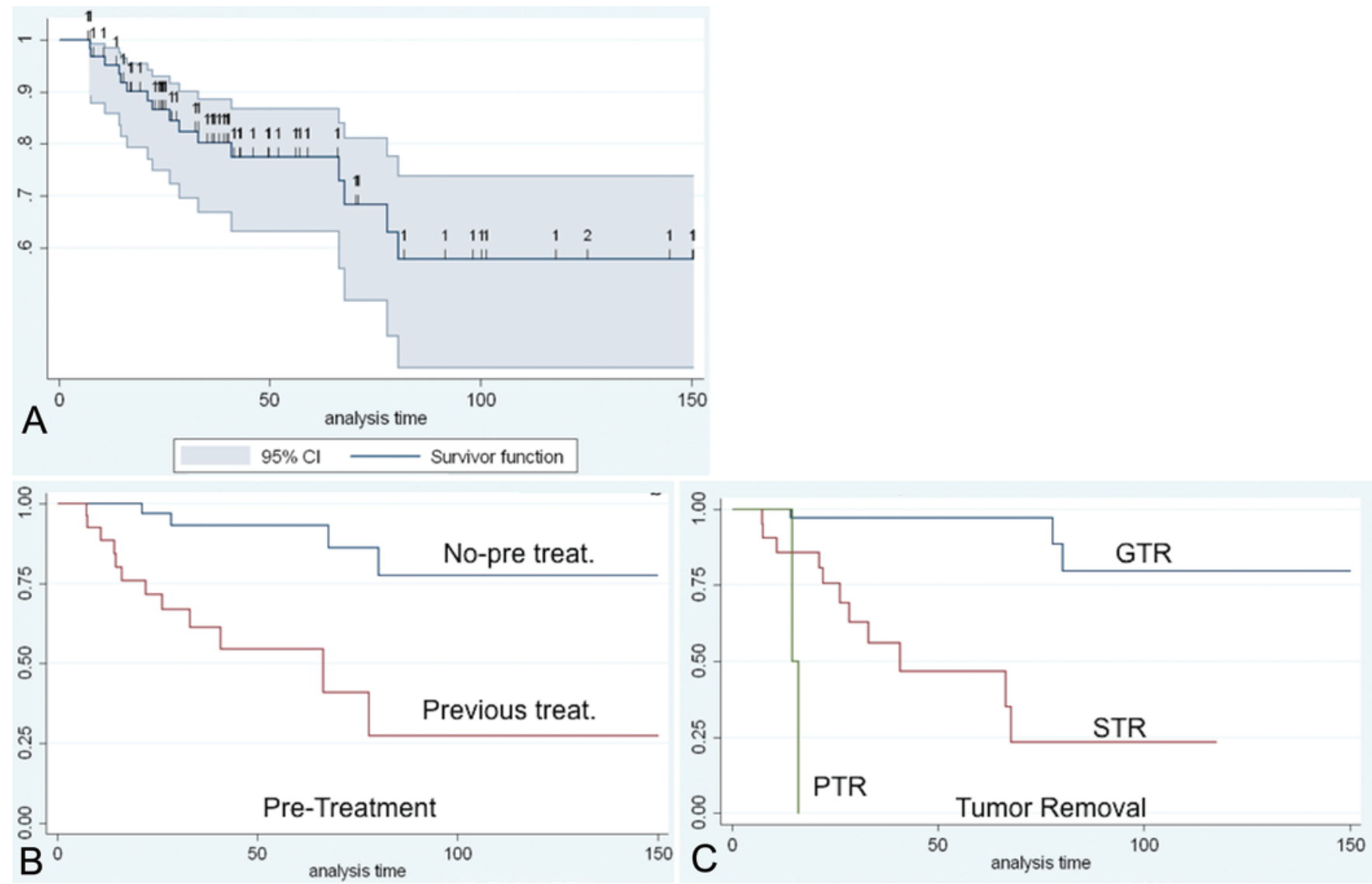

FIG. 7. A: Kaplan-Meier curve for survival rate in the series. B: Kaplan-Meier curve evaluated in terms of previous treatments. It is clearly visible that the survival rate is higher for cases with no previous treatment (No-pre treat.). C: Kaplan-Meier curve evaluated in terms of tumor removal. The role of GTR in determining a higher survival rate is evident. Figure is available in color online only.

TABLE 8. Multivariate analysis to assess which factors have a prognostic role in the survival rate

\begin{tabular}{|c|c|c|c|c|}
\hline Variable & HR Crude $(95 \% \mathrm{Cl})$ & $p$ Value & HR Correct $(95 \% \mathrm{Cl})$ & $\mathrm{p}$ Value \\
\hline Age (for variation of $1 \mathrm{yr}$ ) & $1.01(0.98-1.04)$ & 0.522 & $1.02(0.99-1.05)$ & 0.237 \\
\hline \multicolumn{5}{|l|}{ Sex } \\
\hline Male & Reference & & Reference & \\
\hline Female & $1.02(0.38-2.72)$ & 0.969 & $0.99(0.35-2.82)$ & 0.991 \\
\hline \multicolumn{5}{|l|}{ Surgery } \\
\hline No previous treatment & Reference & & Reference & \\
\hline Previous treatment & $6.68(2.12-21.08)$ & 0.001 & $7.92(2.25-27.89)$ & 0.001 \\
\hline \multicolumn{5}{|l|}{ Location } \\
\hline Extradural & Reference & & Reference & \\
\hline Extradural w/ dural infiltration & $2.92(0.37-23.31)$ & 0.311 & $0.72(0.05-9.91)$ & 0.808 \\
\hline Intradural & $2.51(0.30-21.00)$ & 0.394 & $0.83(0.08-8.96)$ & 0.875 \\
\hline \multicolumn{5}{|l|}{ Clivus } \\
\hline Superior & Reference & & Reference & \\
\hline Inferior & $1.70(1.05-6.62)$ & 0.291 & $1.54(0.50-4.75)$ & 0.448 \\
\hline \multicolumn{5}{|l|}{ Tumor removal } \\
\hline GTR & Reference & & Reference & \\
\hline PTR \& STR & $11.79(3.31-42.07)$ & 0.001 & $10.52(1.62-68.34)$ & 0.001 \\
\hline
\end{tabular}




\section{References}

1. Al-Mefty O, Borba LA: Skull base chordomas: a management challenge. J Neurosurg 86:182-189, 1997

2. Al-Mefty O, Kadri PAS, Hasan DM, Isolan GR, Pravdenkova S: Anterior clivectomy: surgical technique and clinical applications. J Neurosurg 109:783-793, 2008

3. Arbolay OL, González JG, González RH, Gálvez YH: Extended endoscopic endonasal approach to the skull base.

Minim Invasive Neurosurg 52:114-118, 2009

4. Ceylan S, Koc K, Anik I: Extended endoscopic approaches for midline skull-base lesions. Neurosurg Rev 32:309-319, 2009

5. Chibbaro S, Cornelius JF, Froelich S, Tigan L, Kehrli P, Debry $\mathrm{C}$, et al: Endoscopic endonasal approach in the management of skull base chordomas-clinical experience on a large series, technique, outcome, and pitfalls. Neurosurg Rev 37:217-225, 2014

6. Cote DJ, Wiemann R, Smith TR, Dunn IF, Al-Mefty O, Laws ER: The expanding spectrum of disease treated by the transnasal, transsphenoidal microscopic and endoscopic anterior skull base approach: a single-center experience 2008-2015. World Neurosurg 84:899-905, 2015

7. de Divitiis E, Cappabianca P, Cavallo LM: Endoscopic transsphenoidal approach: adaptability of the procedure to different sellar lesions. Neurosurgery 51:699-707, 2002

8. Dehdashti AR, Karabatsou K, Ganna A, Witterick I, Gentili F: Expanded endoscopic endonasal approach for treatment of clival chordomas: early results in 12 patients. Neurosurgery 63:299-309, 2008

9. Diaz-Gonzalez FJ, Padrón A, Foncea AM, García de Sola R, Naval L, Rubio P: A new transfacial approach for lesions of the clivus and parapharyngeal space: the partial segmented Le Fort I osteotomy. Plast Reconstr Surg 103:955-959, 1999

10. Fatemi N, Dusick JR, Gorgulho AA, Mattozo CA, Moftakhar P, De Salles AAF, et al: Endonasal microscopic removal of clival chordomas. Surg Neurol 69:331-338, 2008

11. Fernandez-Miranda JC, Gardner PA, Snyderman CH, Devaney KO, Mendenhall WM, Suárez C, et al: Clival chordomas: a pathological, surgical, and radiotherapeutic review. Head Neck 36:892-906, 2014

12. Frank G, Sciarretta V, Calbucci F, Farneti G, Mazzatenta D, Pasquini E: The endoscopic transnasal transsphenoidal approach for the treatment of cranial base chordomas and chondrosarcomas. Neurosurgery 59 (1 Suppl 1): ONS50-ONS57, 2006

13. Fraser JF, Nyquist GG, Moore N, Anand VK, Schwartz TH: Endoscopic endonasal transclival resection of chordomas: operative technique, clinical outcome, and review of the literature. J Neurosurg 112:1061-1069, 2010

14. Gardner PA, Tormenti MJ, Pant H, Fernandez-Miranda JC, Snyderman $\mathrm{CH}$, Horowitz MB: Carotid artery injury during endoscopic endonasal skull base surgery: incidence and outcomes. Neurosurgery 73 (2 Suppl Operative):ons261ons269, 2013

15. George B, Bresson D, Herman P, Froelich S: Chordomas: a review. Neurosurg Clin N Am 26:437-452, 2015

16. Hong Jiang W, Ping Zhao S, Hai Xie Z, Zhang H, Zhang J, Yun Xiao J: Endoscopic resection of chordomas in different clival regions. Acta Otolaryngol 129:71-83, 2009

17. Katz S, Ford AB, Moskowitz RW, Jackson BA, Jaffe MW: Studies of illness in the aged. The index of ADL: a standardized measure of biological and psychological function. JAMA 185:914-919, 1963

18. Klimo P Jr, Browd SR, Pravdenkova S, Couldwell WT, Walker ML, Al-Mefty O: The posterior petrosal approach: technique and applications in pediatric neurosurgery. J Neurosurg Pediatr 4:353-362, 2009

19. Komotar RJ, Starke RM, Raper DM, Anand VK, Schwartz
TH: The endoscope-assisted ventral approach compared with open microscope-assisted surgery for clival chordomas. World Neurosurg 76:318-327, 259-262, 2011

20. Koutourousiou M, Gardner PA, Tormenti MJ, Henry SL, Stefko ST, Kassam AB, et al: Endoscopic endonasal approach for resection of cranial base chordomas: outcomes and learning curve. Neurosurgery 71:614-625, 2012

21. Lanzino G, Sekhar LN, Hirsch WL, Sen CN, Pomonis S, Snyderman CH: Chordomas and chondrosarcomas involving the cavernous sinus: review of surgical treatment and outcome in 31 patients. Surg Neurol 40:359-371, 1993

22. Leonetti JP, Anderson DE, Marzo SJ, Origitano TC, Schuman R: The preauricular subtemporal approach for transcranial petrous apex tumors. Otol Neurotol 29:380383, 2008

23. Mangussi-Gomes J, Beer-Furlan A, Balsalobre L, Vellutini EA, Stamm AC: Endoscopic endonasal management of skull base chordomas: surgical technique, nuances, and pitfalls. Otolaryngol Clin North Am 49:167-182, 2016

24. Mohyeldin A, Prevedello DM, Jamshidi AO, Ditzel Filho LF, Carrau RL: Nuances in the treatment of malignant tumors of the clival and petroclival region. Int Arch Otorhinolaryngol 18 (2 Suppl 2):S157-S172, 2014

25. Sekhar L, Mantovani A, Mortazavi M, Schwartz TH, Couldwell WT: Open vs endoscopic: when to use which. Neurosurgery 61 (Suppl 1):84-92, 2014

26. Solares CA, Grindler D, Luong A, Kanowitz SJ, Sade B, Citardi MJ, et al: Endoscopic management of sphenoclival neoplasms: anatomical correlates and patient outcomes. Otolaryngol Head Neck Surg 142:315-321, 2010

27. Stippler M, Gardner PA, Snyderman CH, Carrau RL, Prevedello DM, Kassam AB: Endoscopic endonasal approach for clival chordomas. Neurosurgery 64:268-278, 2009

28. Swearingen B, Joseph M, Cheney M, Ojemann RG: A modified transfacial approach to the clivus. Neurosurgery 36:101-105, 1995

29. Vellutini EAS, Balsalobre L, Hermann DR, Stamm AC: The endoscopic endonasal approach for extradural and intradural clivus lesions. World Neurosurg 82 (6 Suppl):S106-S115, 2014

30. Zhang Q, Kong F, Yan B, Ni Z, Liu H: Endoscopic endonasal surgery for clival chordoma and chondrosarcoma. ORL J Otorhinolaryngol Relat Spec 70:124-129, 2008

\section{Disclosures}

The authors report no conflict of interest concerning the materials or methods used in this study or the findings specified in this paper.

\section{Author Contributions}

Conception and design: Milanese, Bonfatti, Faustini-Fustini. Acquisition of data: Zoli, Milanese, Bonfatti, Marucci. Analysis and interpretation of data: Zoli, Milanese, Bonfatti, FaustiniFustini, Marucci. Drafting the article: Zoli, Milanese, Bonfatti. Critically revising the article: Zoli, Milanese, Faustini-Fustini, Marucci, Tallini, Sturiale, Frank, Pasquini, Mazzatenta. Reviewed submitted version of manuscript: Tallini, Sturiale, Frank, Mazzatenta. Statistical analysis: Zenesini, Pasquini. Study supervision: Sturiale, Frank, Pasquini, Mazzatenta.

\section{Correspondence}

Matteo Zoli, Center of Surgery for Pituitary Tumors and Endoscopic Skull Base Surgery, IRCCS Scienze Neurologiche, Bologna 40139, Italy. email: matteo.zoli4@unibo.it. 